\title{
Comprehensive investigation of structural, dielectric and local piezoelectric properties of KNN ceramics
}

\author{
Poonam Kumari*, Madan Lal*, Sunil Kumar ${ }^{\dagger}$, Radheshyam Rai*,\|, Anupinder $\mathrm{Singh}^{\dagger}$,

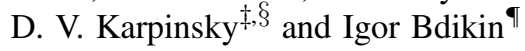 \\ *Department of Physics, ACBS \\ Eternal University, Baru Sahib 173101 \\ Himachal Pradesh, India \\ ${ }^{\dagger}$ Department of Physics, Guru Nanak Dev University \\ Amritsar 143005, India \\ ${ }^{\ddagger}$ Scientific-Practical Materials Research Centre of NAS of Belarus \\ Minsk 220072, Belarus, India \\ $\S$ National Research University of Electronic Technology "MIET" \\ Zelenograd 124498, Moscow, Russia \\ ${ }^{\top}$ TEMA-NRD, Mechanical Engineering Department and Aveiro \\ Institute of Nanotechnology (AIN) \\ University of Aveiro, Aveiro 3810-193, Portugal \\ |rshyam1273@gmail.com
}

Received 8 December 2018; Revised 12 March 2019; Accepted 21 March 2019; Published 6 May 2019

\begin{abstract}
In this research paper, we utilized the traditional high-temperature solid-state reaction method to fabricate the $\mathrm{K}_{0.495} \mathrm{Na}_{0.520} \mathrm{NbO}_{3}$, $\mathrm{K}_{0.480} \mathrm{Na}_{0.535} \mathrm{NbO}_{3}$ and $\mathrm{K}_{0.475} \mathrm{Na}_{0.540} \mathrm{NbO}_{3}$ (abbreviated as $\mathrm{KNN}-1, \mathrm{KNN}-2$, and $\mathrm{KNN}-3$, respectively) lead-free ion deficient ceramics for understanding the influence of ionic deficiency on the crystalline structure and dielectric/piezoelectric properties of the samples. X-ray diffraction patterns of these samples exhibited a perovskite tetragonal phase. Dielectric anomalies around $287^{\circ} \mathrm{C}$ and $471^{\circ} \mathrm{C}$ were identified as ferroelectric to ferroelectric and ferroelectric to paraelectric-transition temperatures for KNN-2 at $1 \mathrm{kHz}$. It was found that the composition $\mathrm{KNN}-2$ exhibit relatively high Curie temperature i.e., $471^{\circ} \mathrm{C}$. The conductivity plots confirm that the activation energies are frequency-dependent. The impedance behavior in our ceramic samples can be analyzed with the bulk/grain effect. The slope of $Z^{\prime}$ with temperature shows negative temperature coefficient of resistance (NTCR) type behavior in proposed $\mathrm{KNN}$ ceramics material.
\end{abstract}

Keywords: KNN; dielectric properties; X-ray diffraction (XRD); NTCR; PFM.

\section{Introduction}

The development of lead-free piezoelectric ceramics has drawn great attention these days due to growing environmental concerns. Currently, the market is dominated by leadbased materials due to their exceptional piezoelectric properties. ${ }^{1}$ Unfortunately, the high concentration of toxic lead - over $60 \mathrm{wt} . \%$ - causes serious harm to human health and contaminates the environment. Due to the toxicity of leadbased compound, we need to develop high-performance leadfree piezoceramics. ${ }^{2}$ There are different kinds of lead-free piezoelectric materials with a perovskite structure that have been widely investigated. They are barium titanate $\left[\mathrm{BaTiO}_{3}\right.$, $\mathrm{BT}$, (Ba,Ca) $(\mathrm{Zr}, \mathrm{Ti}) \mathrm{O}_{3}$ (BCZT)-based, ${ }^{3-7}$ sodium-bismuth titanate $\left[(\mathrm{Bi}, \mathrm{Na}) \mathrm{TiO}_{3}, \mathrm{BNT}\right], \mathrm{BiFeO}_{3}$-based ${ }^{8-10}$ and potassiumsodium niobate $\left[(\mathrm{K}, \mathrm{Na}) \mathrm{NbO}_{3}, \mathrm{KNN}\right]$. Recently, the structure of a rhombohedral-tetragonal $(\mathrm{R}-\mathrm{T})$ phase boundary was reported to effectively improve the piezoelectric properties of KNN-based ceramics resulting in giant $d_{33}$ values of 490-570 $\mathrm{pC} / \mathrm{N} .^{3}$ Zhao et al. reported the highest piezoelectric properties of $\mathrm{K}_{x} \mathrm{Na}_{1-x} \mathrm{NbO}_{3}$ at the optimum $\mathrm{Na} /$ $\mathrm{K}$ ratio of $0.535 / 0.480$. Furthermore, in our preliminary work, the highest dielectric properties were observed in the 0.95 $\left(\mathrm{K}_{x} \mathrm{Na}_{1-x}\right) \mathrm{NbO}_{3}-0.05 \mathrm{LiTaO}_{3}$ system. According to another paper, the Na-rich region exhibited higher piezoelectric properties compare to the K-rich region in $\mathrm{KNN}$ ceramics. Luo et al. reported the effects of low concentration of $\mathrm{Na}$ on the phase structure, dielectric and electrical properties of KNN ceramics. ${ }^{3}$ These confirm that the electrical properties can be enhanced by KNN ceramics with an excess of $\mathrm{Na}$ addition during different steps of synthesis and fabrication. ${ }^{11}$ The reason for excessive $\mathrm{K}$ and $\mathrm{Na}$ are added in precursor to compensate their volatilization during the annealing process which creates A-site vacancies. Due to this, the formation of large amounts of oxygen vacancies and electron holes in

This is an Open Access article published by World Scientific Publishing Company. It is distributed under the terms of the Creative Commons Attribution 4.0 (CC-BY) License. Further distribution of this work is permitted, provided the original work is properly cited. 
$\mathrm{KNN}$ increases the dielectric loss. Many researchers reported that a $10 \mathrm{~mol} . \% \mathrm{~K}$ and $\mathrm{Na}$ excess precursor solution was effective in compensating A-site vacancies and improved the crystallinity and the electrical properties. ${ }^{12,13}$ Therefore, excessive A-site ion on the phase and electrical properties of the KNN ceramic was investigated.

The aim of the present work is to achieve high dielectric constant and Piezo-response force microscopy (PFM) response for device applications. To understand the structural, electrical and ferroelectric domain behavior, these applications were briefly studied by using XRD, Impedance study and PFM. We synthesized all the ionic deficient ceramics of $\mathrm{KNN}$ (i.e., KNN-1, KNN-2, and $\mathrm{KNN}-3$, respectively) in a user-friendly fabrication procedure (solid-State Reaction Method) and found good dielectric properties for devices applications.

\section{Experimental}

$\mathrm{KNN}-1, \mathrm{KNN}-2$ and $\mathrm{KNN}-3$ ceramics were prepared by the conventional solid-state reaction route. The starting materials were high purity oxide and carbonate powders, $\mathrm{K}_{2} \mathrm{CO}_{3}$ (>99.8\%), $\mathrm{Na}_{2} \mathrm{CO}_{3}(>99.8 \%)$ and $\mathrm{Nb}_{2} \mathrm{O}_{5}(>99.9 \%)$. The powders were weighed according to the stoichiometric proportion for different required compositions and mixed using mortar pestle in ethanol media for $6 \mathrm{~h}$. The powders were calcined at $900^{\circ} \mathrm{C}$ for $4 \mathrm{~h}$. After that, the resulting powders were mixed thoroughly with a PVA binder solution. The green pellets were prepared by pressing powders in a $10 \mathrm{~mm}$ diameter die at $100 \mathrm{MPa}$, then sintered at $950^{\circ} \mathrm{C}$ for $5 \mathrm{~h}$ at heating rate of $3.16^{\circ} \mathrm{C} / \mathrm{min}$ and finally cooled to room temperature at $180^{\circ} \mathrm{C} / \mathrm{h}$. The phase formation of ceramics was checked with the help of X-ray powder diffractometer (Rigaku Minifiex 600, Japan) with $\mathrm{CuK} \alpha$ radiation $(\lambda=1.5405 \AA)$ in an extensive range of Bragg angles $2 \theta$ $\left(20^{\circ} \leq 2 \theta \leq 60^{\circ}\right)$ at a scanning rate of $2^{\circ} \mathrm{min}^{-1}$ at room temperature. The polished surfaces of the sintered samples were electrode with air-drying silver paste. Impedance of the samples was studied using Impedance analyzer (Hioki IM3570, Japan) within the frequency window from $1 \mathrm{kHz}$ to $1 \mathrm{MHz}$ at a temperature interval of $5^{\circ}$ from RT to $600^{\circ} \mathrm{C}$. Atomic Force Microscopy (AFM) measurements were carried out using a Veeco AFM Multimode Nanoscope (IV) MMAFM-2, Veeco microscopy. Local piezoelectric properties of the fibers were visualized simultaneously by using AFM in contact mode and PFM methods. ${ }^{14}$

\section{Result and Discussions}

Figure 1 shows the Room temperature XRD patterns of KNN-1, KNN-2 and KNN-3 ceramics prepared by solid-state reaction method. It was found that $\mathrm{KNN}-1$ has monoclinic phase whereas in $\mathrm{KNN}-2$ and $\mathrm{KNN}-3$, the existence of (001/ 100), (101), (002/200), (201/210) and (112/211) which are major lattice planes in the XRD pattern confirms the formation of the orthorhombic structure. In these compositions, there are small amounts of secondary phase $\mathrm{K}_{2} \mathrm{Nb}_{6} \mathrm{O}_{16}$ (as shown by which are detectable. ${ }^{15}$ The XRD confirmed that

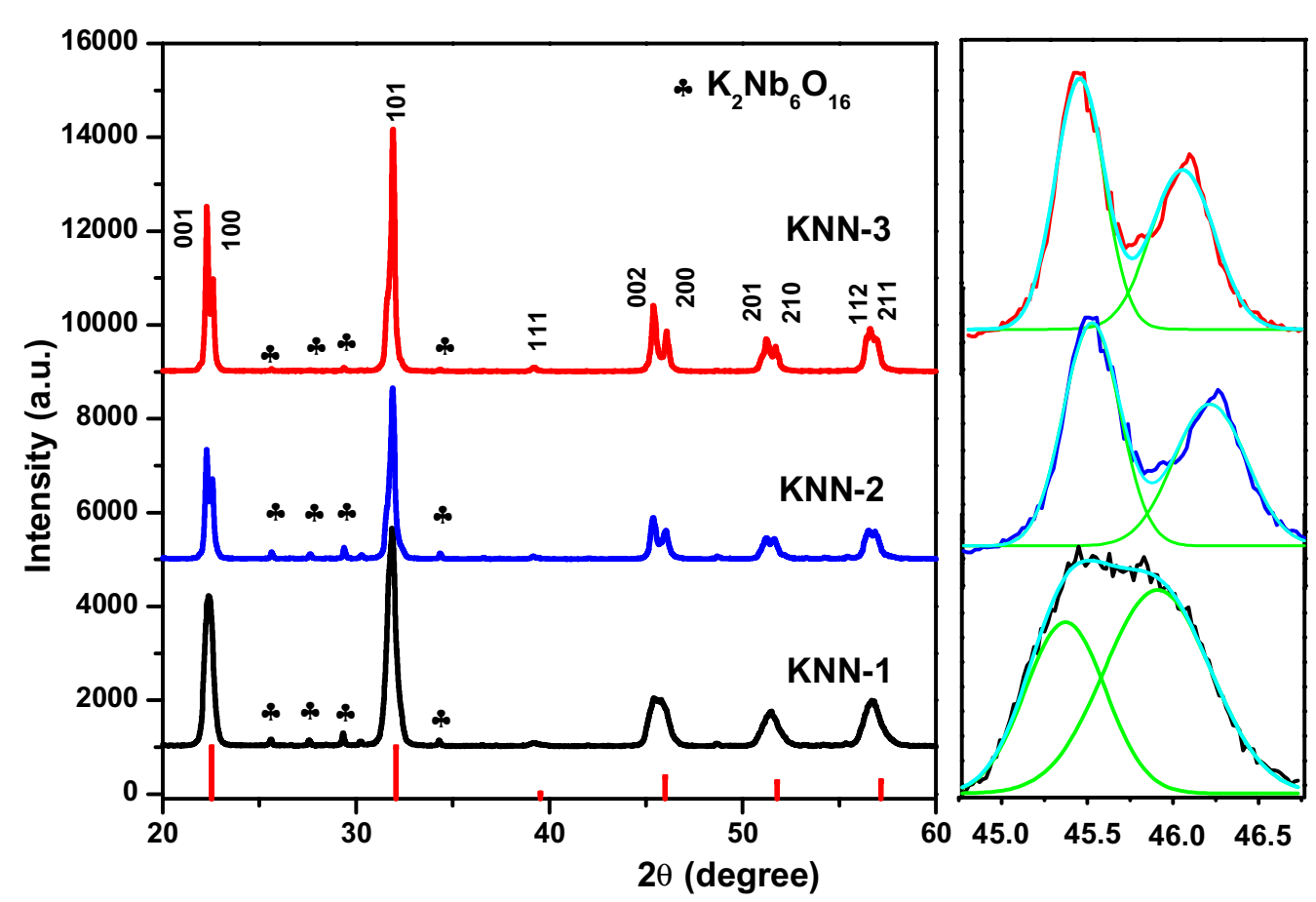

Fig. 1. Room temperature XRD patterns of $\mathrm{K}_{0.495} \mathrm{Na}_{0.520} \mathrm{NbO}_{3}$, (KNN-1) $\mathrm{K}_{0.480} \mathrm{Na}_{0.535} \mathrm{NbO}_{3}(\mathrm{KNN}-2)$ and $\mathrm{K}_{0.475} \mathrm{Na}_{0.540} \mathrm{NbO}_{3}\left(\mathrm{KNN}^{-3}\right)$ compositions calcined at $9000^{\circ} \mathrm{C}$ for $4 \mathrm{~h}$. 


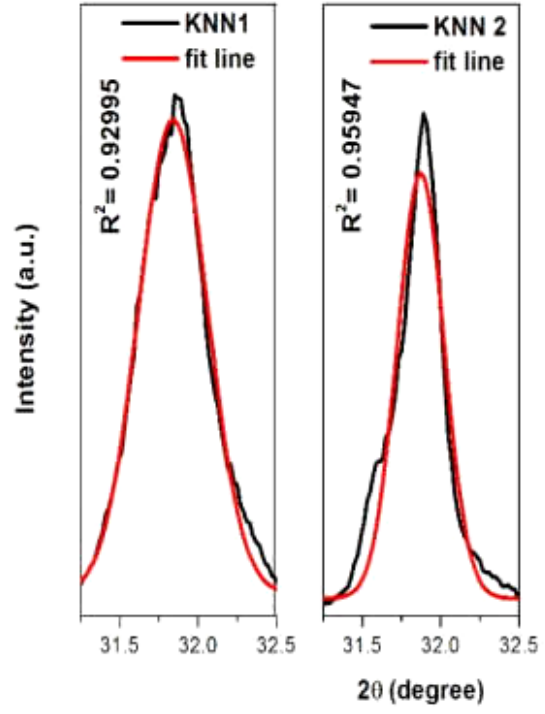

(a)
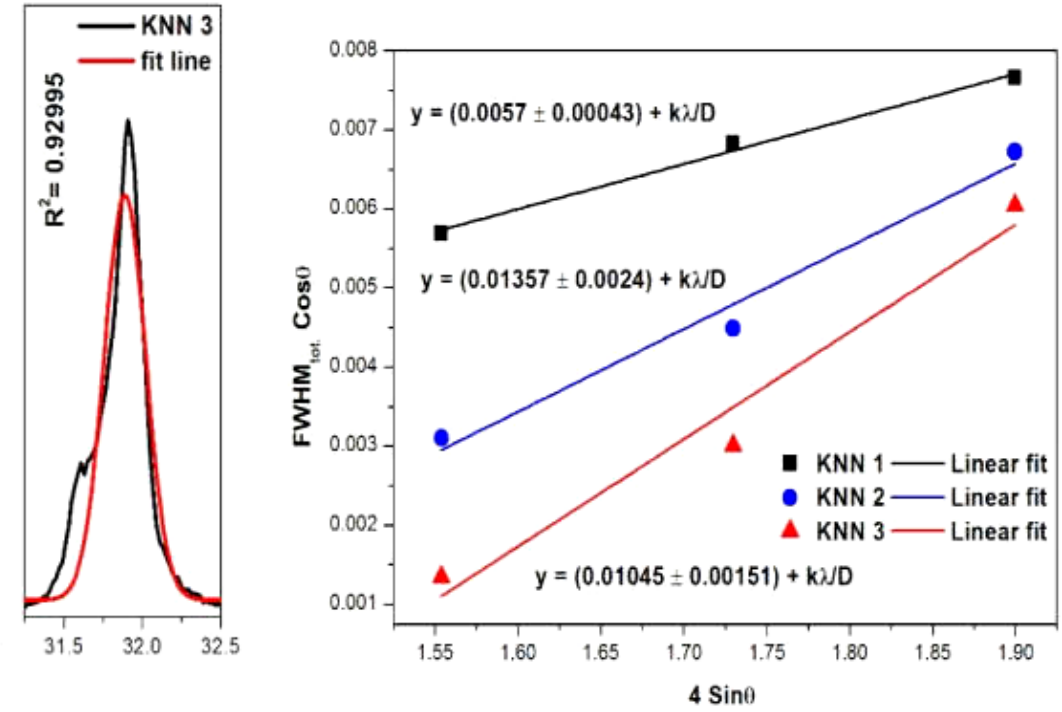

(b)

Fig. 2. (a) XRD peaks from the (110), (011), (200) and (201) planes of KNN-1, KNN-2 and KNN-3 ceramic fitted to the Gaussian function, and (b) Variations of $\mathrm{FWHM}_{\text {tot. }} \cos \theta$ with $4 \sin \theta$ for $\mathrm{KNN}-1, \mathrm{KNN}-2$ and $\mathrm{KNN}-3$, respectively.
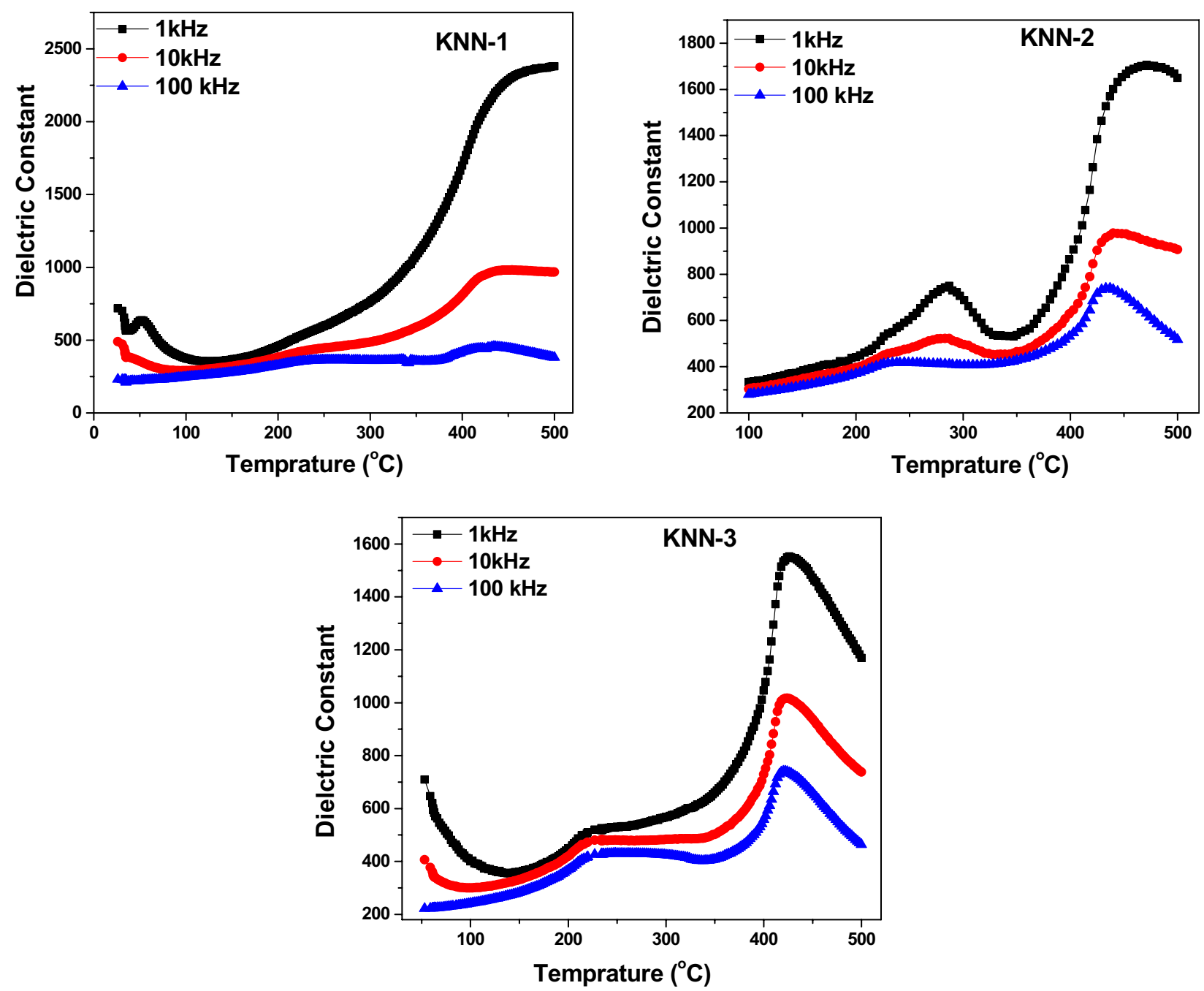

Fig. 3. The variation of dielectric constant $\left(\varepsilon^{\prime}\right)$ as function of temperature of KNN-1, KNN-2, and KNN-3 ceramics at different frequencies. 
the major perovskite phase exists in structure and minor secondary phase $\left(\mathrm{K}_{2} \mathrm{Nb}_{6} \mathrm{O}_{16}\right)$ exists in $\mathrm{KNN}$ ceramics. The calculated and observed ' $\mathrm{d}$ ' values of all diffraction lines (reflections) of the above compounds suggest that there is a change in the basic crystal structure as compositions change due to the more volatile behavior of $\mathrm{Na}$ on high temperature. Therefore, at high sintering temperature, the samples are made with $\mathrm{K}$-rich content, and as the radius of $\mathrm{K}^{+}(1.33 \AA)$ is larger than that of $\mathrm{Na}^{+}(0.97 \AA)$, this gives rise to an eventually increased crystal parameter. In our samples, the intensity increases with the increase in the concentrations of $\mathrm{Na}$. It reflects the decrease in crystallinity with $\mathrm{Na}$ concentration.

Figure 2(a) shows the fitting of XRD peak for (101) lattice plane for $\mathrm{KNN}-1, \mathrm{KNN}-2$ and $\mathrm{KNN}-3$ ceramics fitted to Gaussian function. The coefficient of determination of fitted peaks to Gaussian function is closer to unity compared to other functions. This coefficient is also symbolized by $R^{2}$ which is interpreted as the goodness of fit of a regression.
An $R^{2}$ close to unity indicates that a regression line fits the data well, whereas an $R^{2}$ closer to zero indicates a poor fit.

Stripping the instrumental, strain and size broadening factors depend on the shape of the peaks. For Gaussian peaks, the relation is defined as follows:

$$
\mathrm{FWHM}_{\text {obs. }}=\mathrm{FWHM}_{\text {size }}+\mathrm{FWHM}_{\text {strain }}+\mathrm{FWHM}_{\text {inst. }} \text {. }
$$

Estimation of the instrumental broadening $\left(\mathrm{FWHM}_{\text {inst. }}\right)$ is desirable to correct the width of different peaks. FWHM inst. $_{\text {. }}$ was determined by fitting the XRD profiles to a Gaussian function. $\mathrm{FWHM}_{\text {tot }}$ involving both $\mathrm{FWHM}_{\text {size. }}$ and FWHM $_{\text {strain }}$ can be expressed as

$$
\mathrm{FWHM}_{\text {tot. }}=\mathrm{FWHM}_{\text {size }}+\mathrm{FWHM}_{\text {strain }},
$$

where

$$
\mathrm{FWHM}_{\text {size. }}=\frac{K}{D \cos \theta} ; \quad \mathrm{FWHM}_{\text {strain }}=C \varepsilon_{0} \tan \theta .
$$
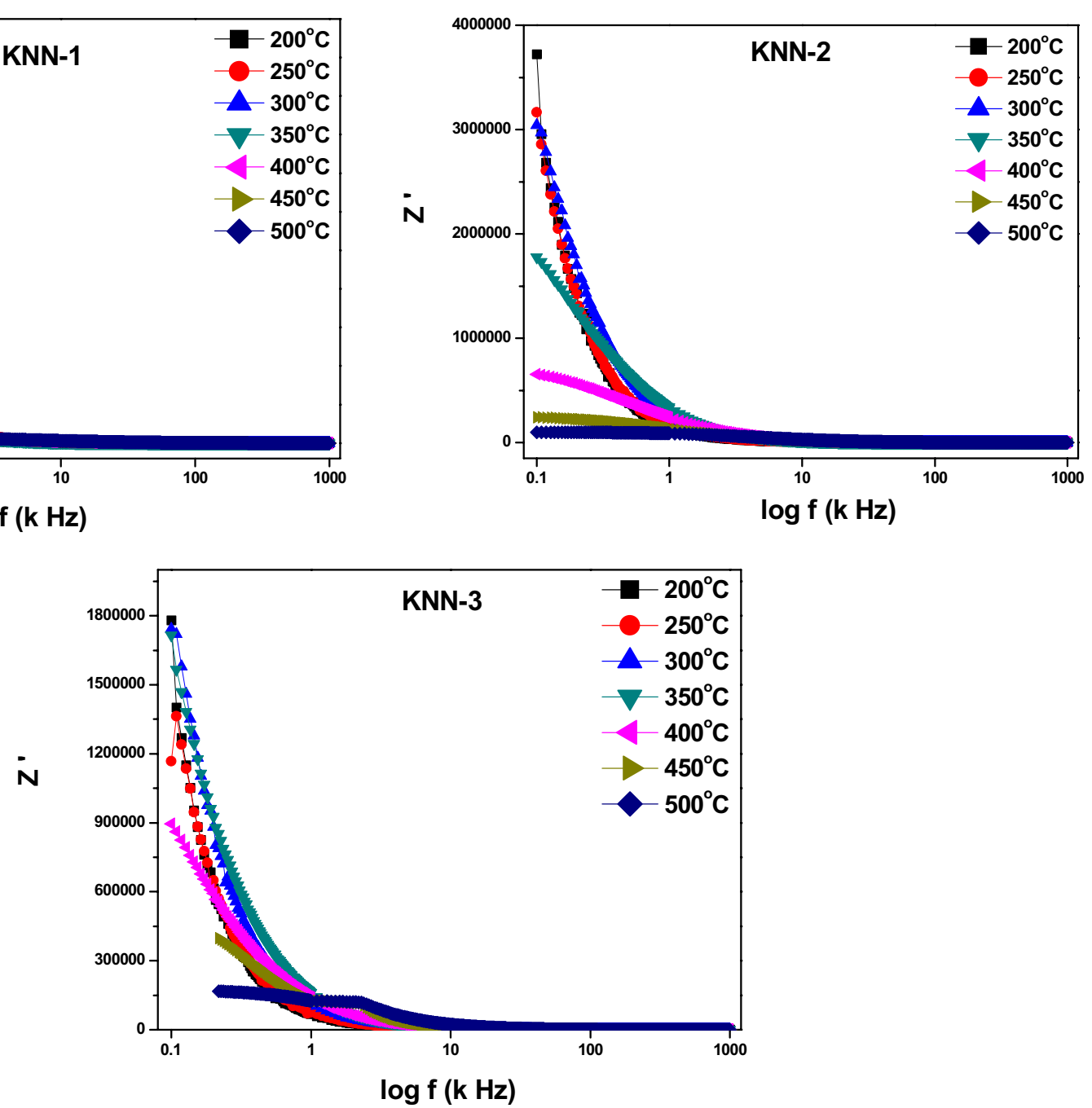

Fig. 4. The variation of real part impedance $\left(Z^{\prime}\right)$ with frequency at different temperature for KNN-1, KNN-2 and KNN-3 ceramics. 

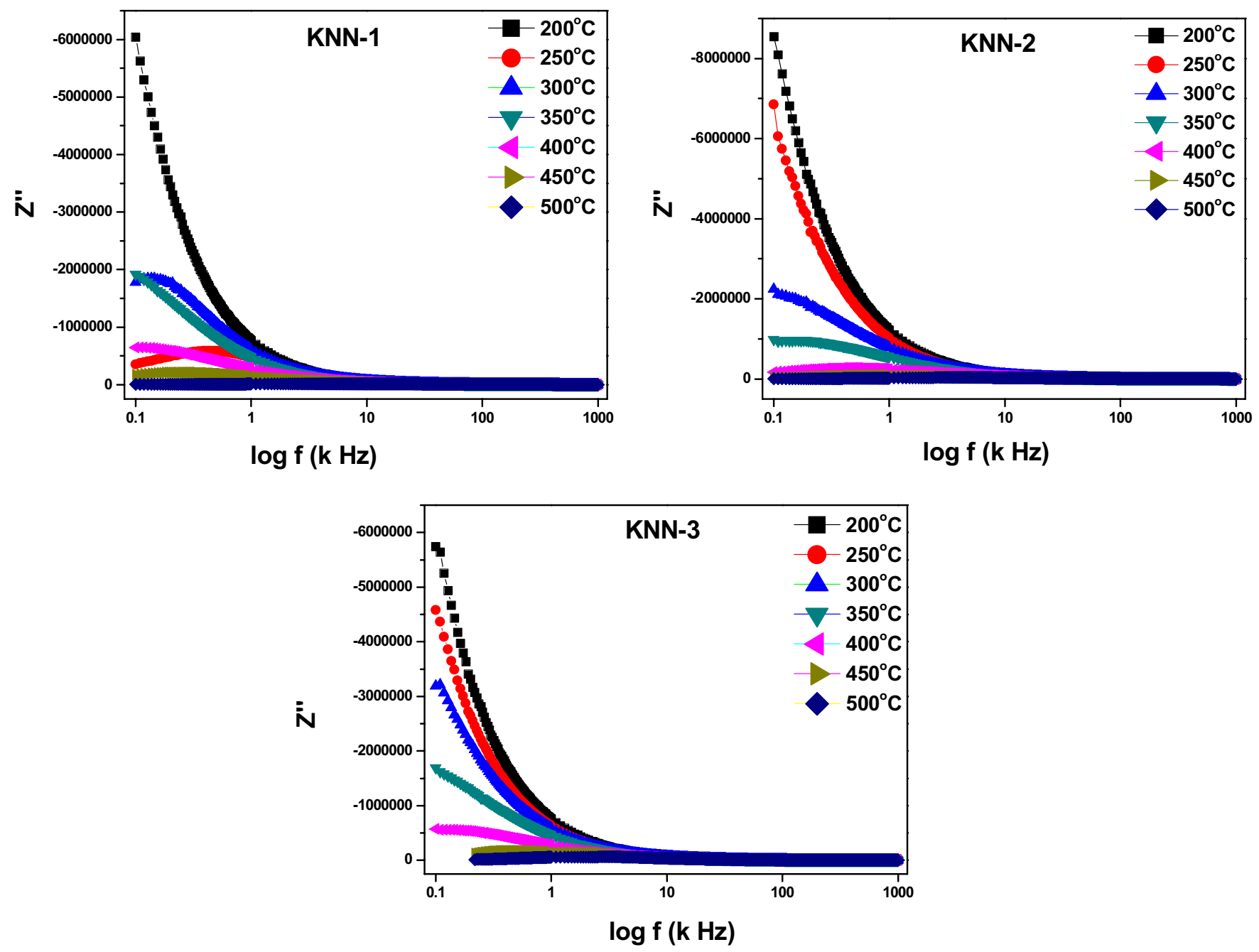

Fig. 5. The variation of imaginary part impedance $\left(Z^{\prime \prime}\right)$ with frequency at different temperature for KNN-1, KNN-2 and KNN-3 ceramics.

Rewriting the equation for lattice strain and particle size effects:

$$
\mathrm{FWHM}_{\text {tot. }}=\left(\mathrm{FWHM}_{\text {obs. }}^{2}-\mathrm{FWHM}_{\text {inst. }}^{2}\right)^{1 / 2} .
$$

Here, $\mathrm{FWHM}_{\mathrm{obs}}$ and $\mathrm{FWHM}_{\text {inst }}$ are the measured peak broadening and instrumental broadening in radian, respectively.

On solving Eq. (3), we have

$$
\text { FWHM }_{\text {tot. }} \cos \theta=\frac{K}{D}+C \varepsilon_{0} \tan \theta .
$$

Here, $D$ is the grain diameter, $k=0.9-1.0$ depending upon grain shape and $C \varepsilon_{0}$ is the strain in material

$$
Y=m x+C .
$$

On comparing (5) and (6), $m=C \varepsilon_{0}=$ slope $=$ strain of sample.

Figure 2(b) shows the variation of $\mathrm{FWHM}_{\text {tot. }} \cos \theta$ with $\sin \theta$ and the slope of this plot is used to calculate the strain of the materials as explained in the above equation and the strain in our materials are $\sim(0.57 \pm 0.043 \%),(1.357 \pm 0.24 \%)$ and $(1.045 \pm 0.151 \%)$. All the reflection lines in XRD pattern were used for obtaining the average crystalline size using the Debye-Scherrer equation. ${ }^{16}$

$$
D=0.9 \lambda / \mathrm{FWHM}_{\text {tot. }} \cos \theta .
$$

Here, $D$ is the diameter of the particle, $\lambda$ is the $\mathrm{x}$-ray wavelength $(0.154 \mathrm{~nm})$, and $\theta$ is the Bragg angle of the reflection. The calculated average crystalline sizes from Eq. (7) are $\sim 30.86,40.50$ and $64.87 \mathrm{~nm}$, respectively.

Figure 3 shows the variation of dielectric constant $\left(\varepsilon^{\prime}\right)$ as a function of the temperature of $\mathrm{KNN}-1, \mathrm{KNN}-2$, and $\mathrm{KNN}-3$ ceramics at different frequencies. $\mathrm{KNN}-2$ and $\mathrm{KNN}-3$ ceramics have a two sharp-phase transitions at $287^{\circ} \mathrm{C}$ and $471^{\circ} \mathrm{C}$, each respectively representing the orthorhombic to tetragonal (at $T^{1}$ ) and tetragonal to paraelectric cubic (at $T^{2}$ or $T_{c}$ ) phase transitions. It is also observed that with an increase of $\mathrm{Na}$, the dielectric constant decreases corresponding to the 

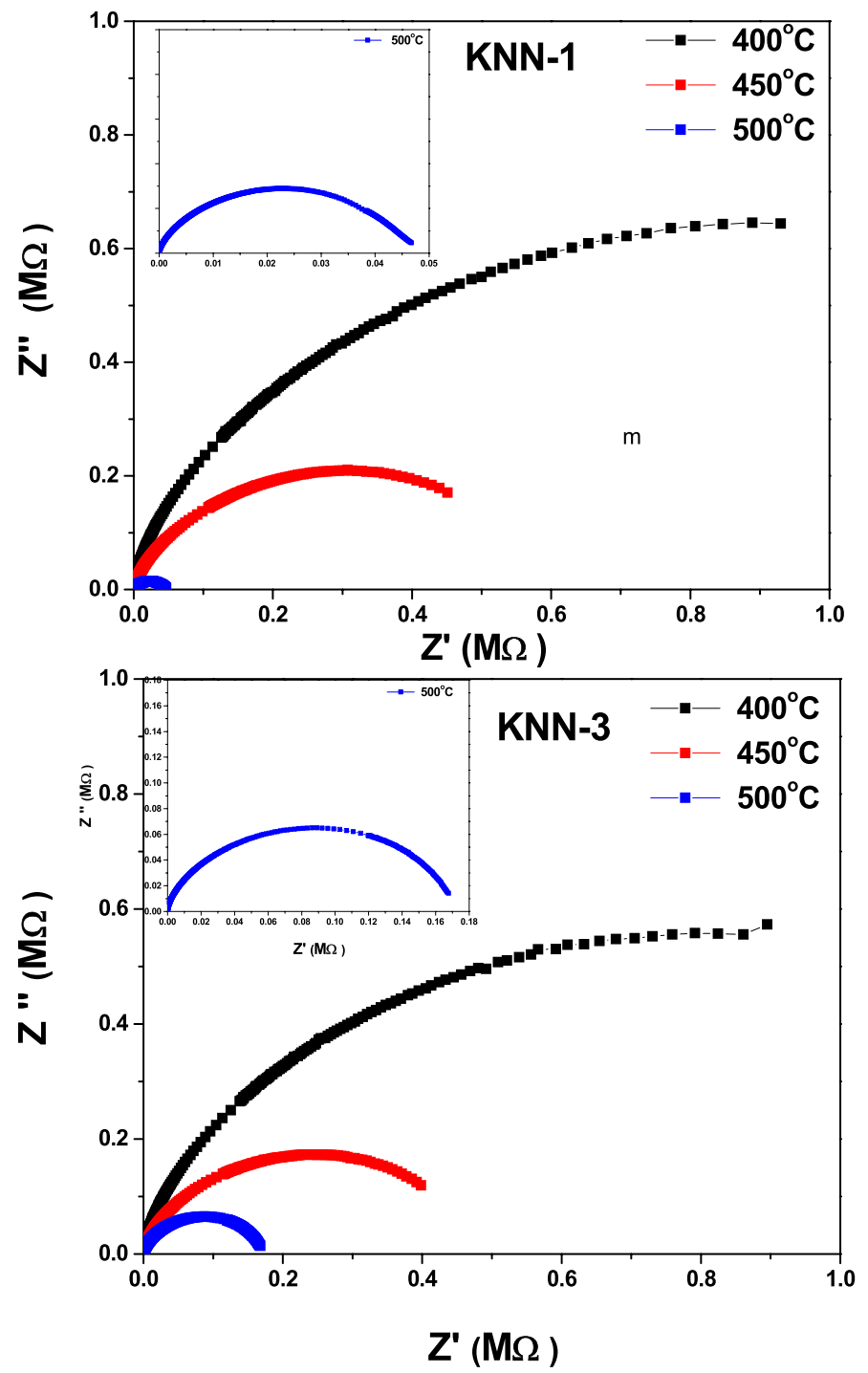
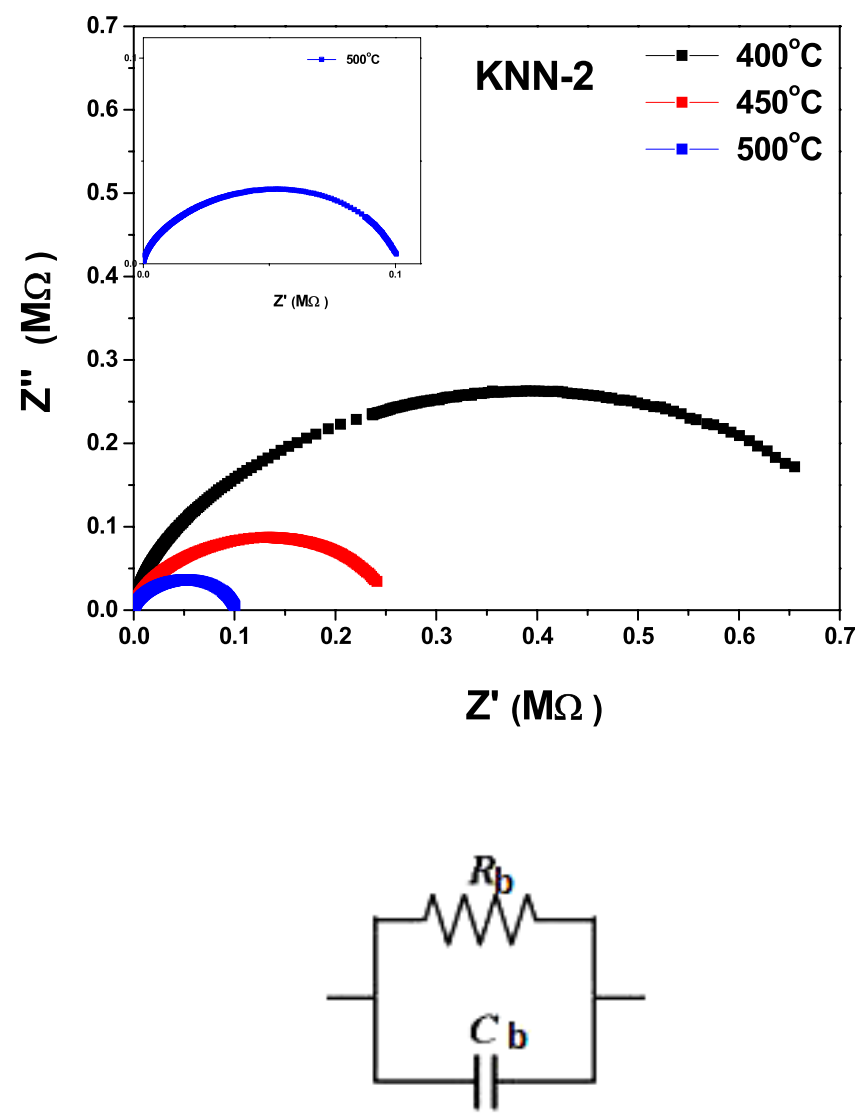

Fig. 6. The Cole-Cole plot of $\mathrm{KNN}-1, \mathrm{KNN}-2$ and $\mathrm{KNN}-3$ samples at different temperature.

ferroelectric-paraelectric phase transition, but the $T^{1}$ phase transition peaks shifted to a little lower temperature from $454^{\circ} \mathrm{C}$ to $422^{\circ} \mathrm{C}$.

Figure 4 shows the variation of the real part of impedance $\left(Z^{\prime}\right)$ with frequency at different temperatures. The pattern shows a sigmoidal variation as a function of frequency in the low-frequency region followed by a saturation region in the high-frequency region (above $1 \mathrm{kHz}$ ) and suggests the presence of mixed nature of polarization behavior in the material. The impedance value is observed to increase first in the low-frequency region with the rise in temperature followed by a relative decrease at subsequently higher temperatures. The result may be related to a change in the chargeordering pattern with temperature; the effect showing a clearly perceptible change in its behavior in the lowfrequency region. A decreasing trend of $Z^{\prime}$ with the rising in temperature suggests the presence of negative temperature coefficient of resistance (NTCR) in the material in the lowfrequency region but tends to merge in the high-frequency region at almost all temperatures. There is a possibility of increase in ac conductivity with the rise in temperature in the high frequency region (possibly) due to the release of space charge. This space charge comes from mobile ions which in the present case could be the oxygen vacancies. ${ }^{17,18}$

Figure 5 exhibits frequency and temperature dependence of imaginary part of impedance $\left(Z^{\prime \prime}\right)$ for KNN solid-solutions. In low-temperature/frequency range, $Z^{\prime \prime}$ has very high value for all the compositions which decreases with the rise in frequency and attains low values. This is an interesting (unusual) trend in the variation of $Z^{\prime \prime}$ with frequency/temperature for $\mathrm{KNN}$ ceramic samples. The appearance and nature of peaks at a characteristic angular frequency $\omega_{\max }\left(=2 \pi f_{\max }\right)$ provides information on the type and strength of the dielectric relaxation phenomenon occurring in the material. At different 

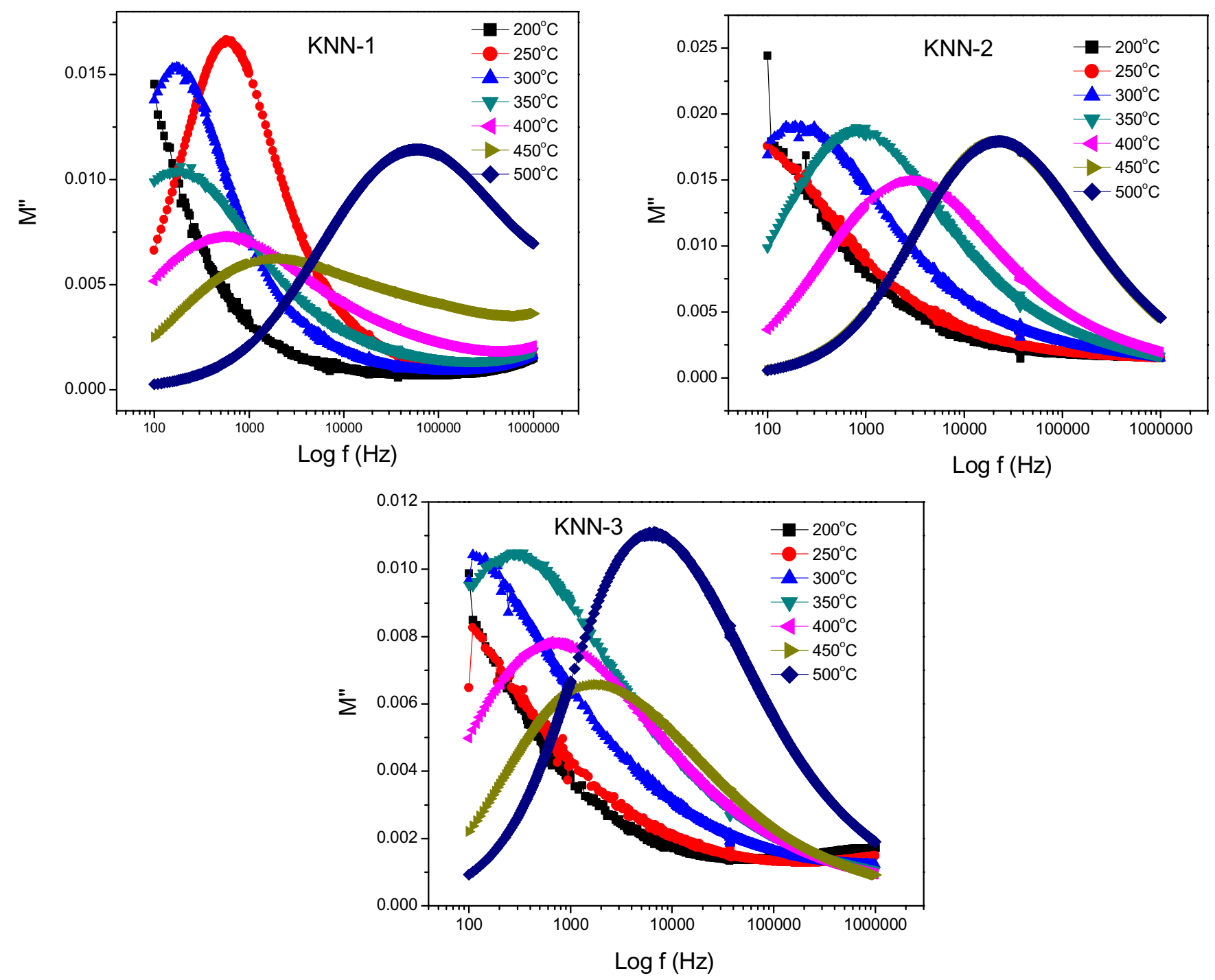

Fig. 7. Variation of imaginary part modulus $\left(M^{\prime \prime}\right)$ with frequency at different temperatures of KNN-1, KNN-2 and KNN-3 ceramics.

temperatures, the spectrum shows a monotonous decrease having dispersive nature of pattern in the low-frequency region followed by a plateau at the higher frequencies. This observation clearly suggests the presence of electronic, dipolar and space charge polarizations in these materials.

The relaxation frequencies can also be obtained from a $Z^{\prime \prime}-Z^{\prime}$ Cole-Cole plot (Nyquist diagram). Figure 6 shows a set of impedance data taken over by a wide range of frequencies at temperatures of $400^{\circ} \mathrm{C}, 450^{\circ} \mathrm{C}$ and $500^{\circ} \mathrm{C}$, respectively. The slopes of the lines of $\mathrm{KNN}$ ceramics decreased in the range of $400-500^{\circ} \mathrm{C}$ and bend towards the real axis. The appearance of semi-arc at maximum temperature indicates that only the bulk grain effect appears in pure $\mathrm{KNN}$ (i.e., only one $R C$ element can represent this behavior). Further, the radii decrease with the increase of temperature, thereby indicating the NTCR nature of the KNN ceramics. Another interesting result for the KNN ceramics is that the
Cole-Cole plots could not be represented by full semicircles until the highest temperature (shown with blue lined color in Fig. 6 (inset)). The semi-circular arc was depressed and the center of the arc was below the $x$-axis. This behavior indicates that this sample has a poly-dispersive non-Debye behavior. A parallel $R C$ equivalent circuit has fitted very well with highfrequency data. ${ }^{19}$

Figure 7 shows the variation of imaginary part of the modulus $\left(M^{\prime \prime}\right)$ with frequency at different temperatures for KNN compound with different $\mathrm{Na}$ content. $M^{\prime \prime}$ shows the strong peaks and the position of the peak, i.e., $M_{\max }^{\prime \prime}$, shifted to higher frequencies as the temperature was increased. The frequency region below peak maximum M" determines the range in which charge carriers are mobile on long distances. At frequency above peak maximum, the carriers are confined to potential wells, being mobile on short distances. The peaks are asymmetric and broader than the 

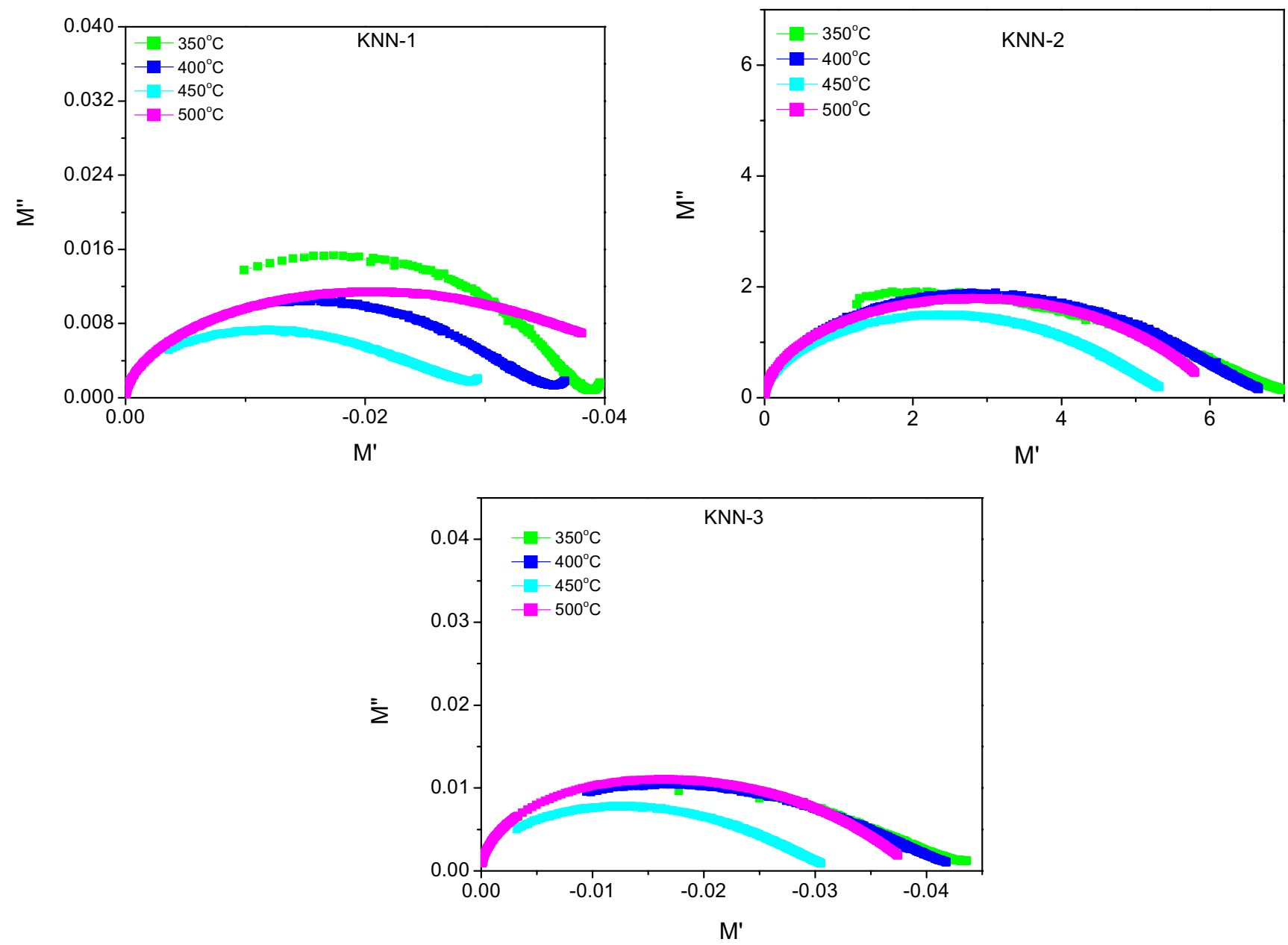

Fig. 8. Variation of real $\left(M^{\prime}\right)$ and imaginary part $\left(M^{\prime \prime}\right)$ of modulus of different temperature of KNN-1, KNN-2 and KNN-3 ceramics.

ideal Debye curve. The frequency range where the peaks occur is indicative of the transition from long range to short range mobility. ${ }^{20}$

The complex electric modulus spectrum $M^{\prime}$ versus $M^{\prime \prime}$ is shown in Fig. 8 for $\mathrm{K}_{1-x} \mathrm{Na}_{x} \mathrm{NbO}_{3}$ ceramics at different temperatures. The patterns are characterized by the presence of little asymmetric and depressed semicircular arcs whose center does not lie on $M^{\prime}$ axis. The behavior of the electric modulus spectrum is suggestive of the temperature-dependent hopping type of mechanism for electric conduction (charge transport) in the system and non-Debye type dielectric relaxation.

Figure 9 shows the normalized plot of $M^{\prime \prime} / M_{\max }^{\prime \prime}$ versus $\log \left(f / f_{\max }\right)$ at different temperatures for KNN ceramics, respectively. The normalized plot overlaps on a single master curve at different temperatures (i.e., same shape and pattern in the peak position with slight variation in full width at half maximum (FWHM) with the rise in temperature). The value of FWHM evaluated from the normalized spectrum is greater than $\log \frac{2+\sqrt{ } 3}{2-\sqrt{ } 3}$, and this indicates the non-Debye type behavior which is well supported by complex modulus plot. $^{21,22}$

The ac conductivity $\left(\sigma_{\mathrm{ac}}\right)$ of the samples was calculated from the dielectric data using the relation $\sigma=\omega \varepsilon \varepsilon 0 \tan \delta$ where $\varepsilon 0$ is the vacuum permittivity and $\omega$ is the angular frequency. The conductivity of all the samples was estimated in the paraelectric temperature range $430-500^{\circ} \mathrm{C}$. The variation of $\ln \sigma_{\mathrm{ac}}$ with temperature $(\mathrm{K}-1)$ is shown in Fig. 10. The activation energy $\left(E_{a}\right)$ of the samples (Table 1) was calculated in the high-temperature region (where the tangent loss is relatively low), using the relation $\sigma=\sigma_{0} \exp \left(-E_{a} / \mathrm{K}\right.$ $\mathrm{BT}$ ), where $K_{B}$ is the Boltzmann constant and $\sigma_{0}$ is the preexponential factor.

AFM measurements were carried out using a Veeco AFM Multimode Nanoscope (IV) MMAFM-2, Veeco microscopy. Local piezoelectric properties of the fibers were visualized simultaneously by using AFM in contact mode and PFM methods. The PFM technique is based on the converse piezoelectric effect, which is a linear coupling between the electrical and mechanical properties of a material. Since 

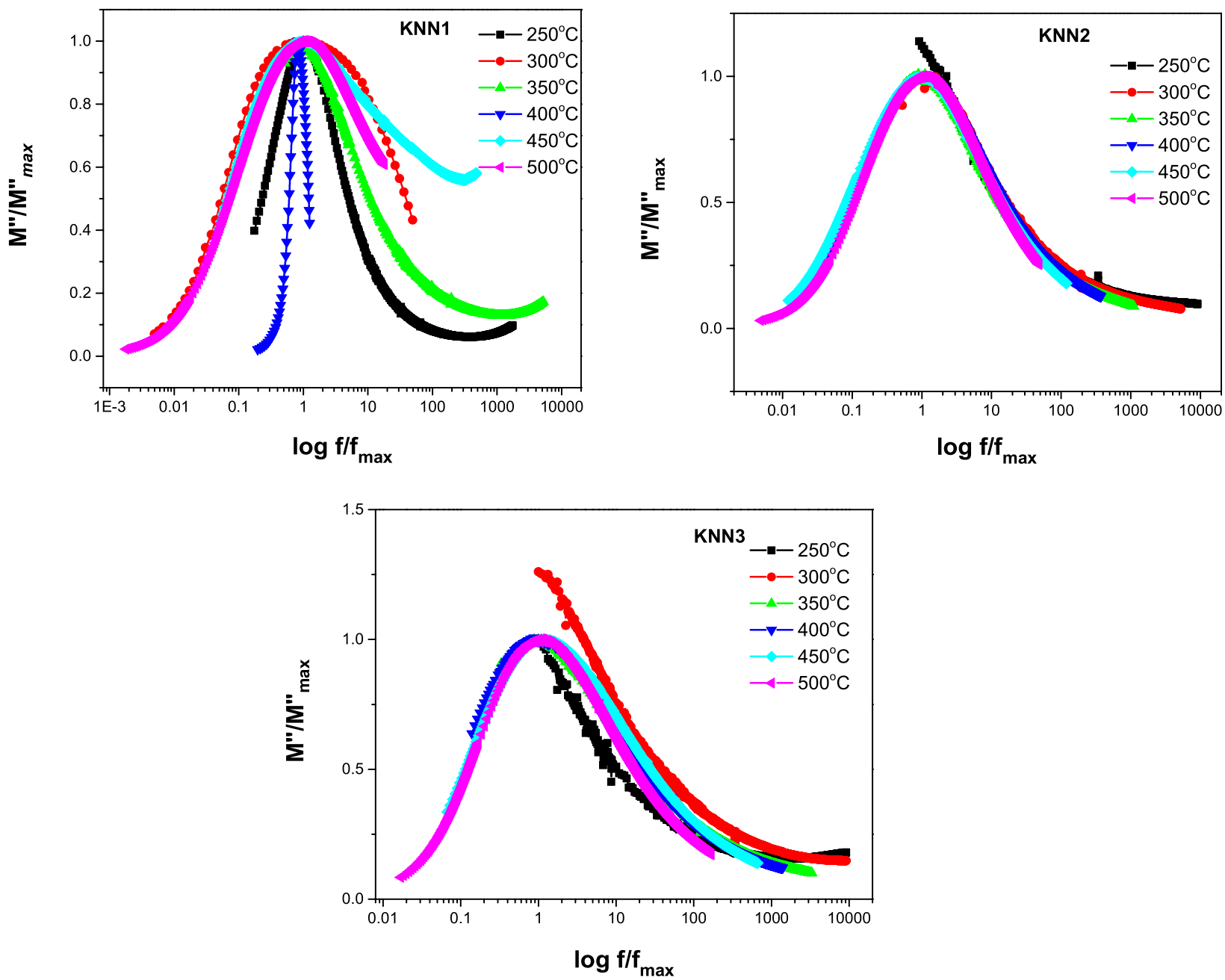

Fig. 9. Modulus scaling behavior of $\mathrm{KNN}-1, \mathrm{KNN}-2$ and $\mathrm{KNN}-3$ ceramics.
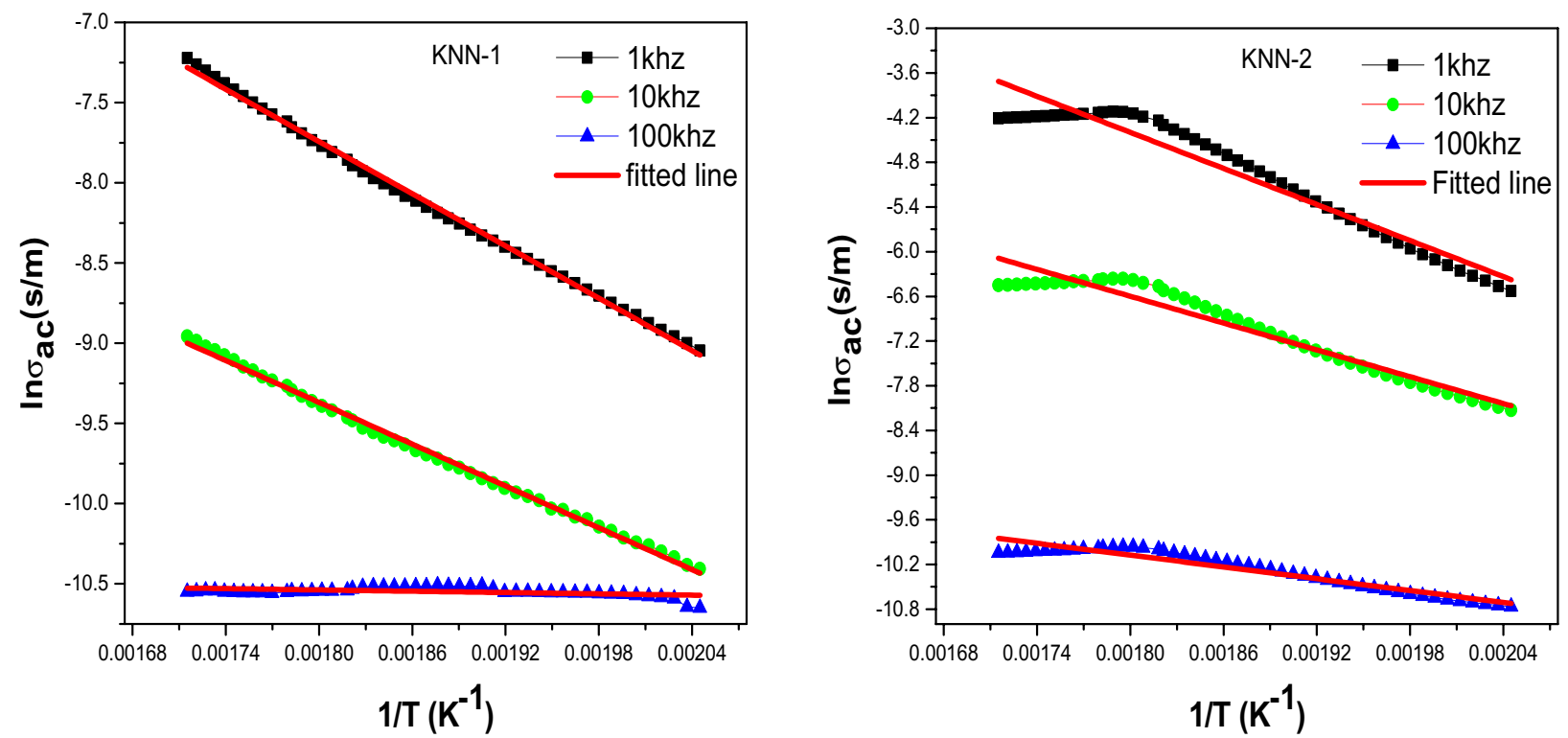

Fig. 10. Variation of ac conductivity $\ln \sigma_{\mathrm{ac}}$ as a function of inverse of absolute temperature $1 / T$ of $\mathrm{KNN}-1, \mathrm{KNN}-2$ and $\mathrm{KNN}-3$ ceramics at $1 \mathrm{kHz}, 10 \mathrm{kHz}$ and $100 \mathrm{kHz}$ frequencies. 


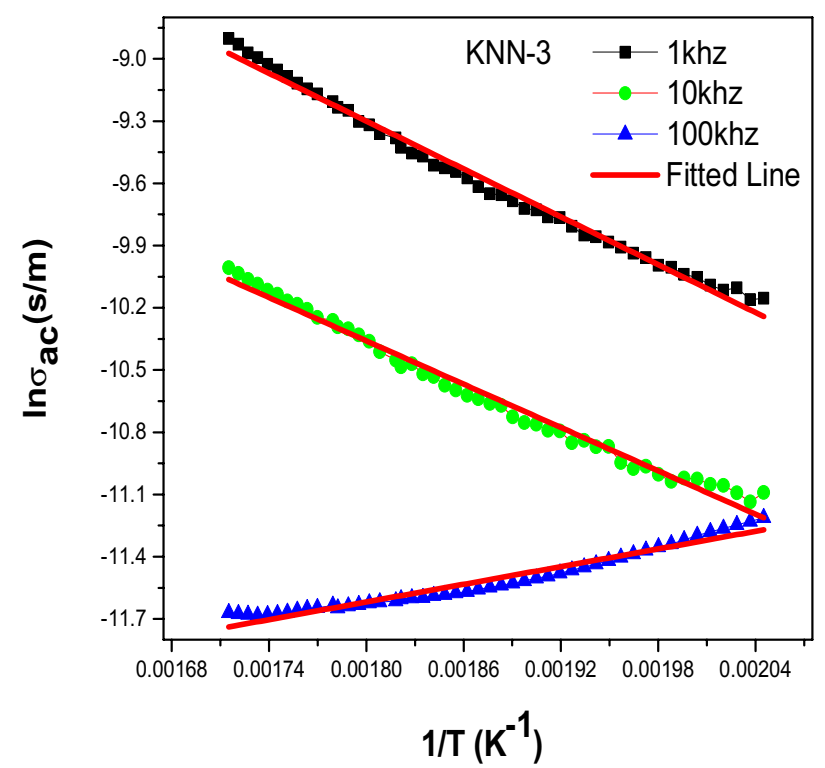

Fig. 10. (Continued)

Table 1. hkl, lattice parameters, and Unit cell Volume of $\mathrm{K}_{0.495} \mathrm{Na}_{0.520} \mathrm{NbO}_{3}$, (KNN-1) $\mathrm{K}_{0.480} \mathrm{Na}_{0.535} \mathrm{NbO}_{3}(\mathrm{KNN}-2)$ and $\mathrm{K}_{0.475} \mathrm{Na}_{0.540} \mathrm{NbO}_{3}$ (KNN-3) compositions.

\begin{tabular}{|c|c|c|c|c|c|}
\hline Composition $(x)$ & Crystalline structure & $d_{\text {obs. }}$ & $d_{\text {cal. }}$ & Lattice parameters $(\AA)$ & Unit cell volume $(\AA)^{3}$ \\
\hline $\mathrm{K}_{0.495} \mathrm{Na}_{0.520} \mathrm{NbO}_{3}(\mathrm{KNN}-1)$ & Tetragonal & $\begin{array}{l}3.9708 \\
2.8073 \\
2.2866 \\
1.9955 \\
1.7733\end{array}$ & $\begin{array}{l}3.9708 \\
2.8073 \\
2.2872 \\
1.9957 \\
1.7731\end{array}$ & $\begin{array}{c}a=11.554 \\
c=11.91 \\
c / a=1.0310\end{array}$ & 1590.40 \\
\hline $\mathrm{K}_{0.480} \mathrm{Na}_{0.535} \mathrm{NbO}_{3}(\mathrm{KNN}-2)$ & & $\begin{array}{l}3.9863 \\
3.4931 \\
2.8246 \\
2.3089 \\
2.0016 \\
1.6336\end{array}$ & $\begin{array}{l}3.9881 \\
3.4937 \\
2.8234 \\
2.3065 \\
2.0021 \\
1.6338\end{array}$ & $\begin{array}{c}a=8.4701 \\
c=18.0825 \\
c / a=2.1349\end{array}$ & 1279.128 \\
\hline $\mathrm{K}_{0.475} \mathrm{Na}_{0.540} \mathrm{NbO}_{3}(\mathrm{KNN}-3)$ & & $\begin{array}{l}4.0123 \\
2.8254 \\
2.7720 \\
2.3016 \\
2.2634 \\
2.0056\end{array}$ & $\begin{array}{l}4.0123 \\
2.8254 \\
2.7716 \\
2.3152 \\
2.2636 \\
2.0062\end{array}$ & $\begin{array}{c}a=101873 \\
c=17.4607 \\
c / a=1.7140\end{array}$ & 1812.09 \\
\hline
\end{tabular}

Table 2. Different physical parameters of of $\mathrm{K}_{0.495} \mathrm{Na}_{0.520} \mathrm{NbO}_{3}$, (KNN-1) $\mathrm{K}_{0.480} \mathrm{Na}_{0.535} \mathrm{NbO}_{3}$ (KNN-2) and $\mathrm{K}_{0.475} \mathrm{Na}_{0.540} \mathrm{NbO}_{3}$ (KNN-3) compositions.

\begin{tabular}{|c|c|c|c|c|c|c|c|c|c|}
\hline \multirow{2}{*}{$\frac{\text { Composition }}{\text { Freq.(kHz)- }}$} & \multicolumn{3}{|c|}{ KNN-1 } & \multicolumn{3}{|c|}{ KNN-2 } & \multicolumn{3}{|c|}{$\mathrm{KNN}-3$} \\
\hline & $1 \mathrm{kHz}$ & $10 \mathrm{kHz}$ & $100 \mathrm{kHz}$ & $1 \mathrm{kHz}$ & $10 \mathrm{kHz}$ & $100 \mathrm{kHz}$ & $1 \mathrm{kHz}$ & $10 \mathrm{kHz}$ & $100 \mathrm{kHz}$ \\
\hline$T^{1}\left({ }^{\circ} \mathrm{C}\right)$ & - & - & - & 287 & 283 & 245 & 234 & 234 & 234 \\
\hline$T^{2}\left({ }^{\circ} \mathrm{C}\right)$ & 454 & 450 & 434 & 471 & 440 & 437 & 426 & 424 & 422 \\
\hline$\varepsilon_{\max }$ & 2303.4 & 981.1 & 456 & 1704.8 & 978.2 & 739.27 & 1552.8 & 1169 & 741.5 \\
\hline
\end{tabular}



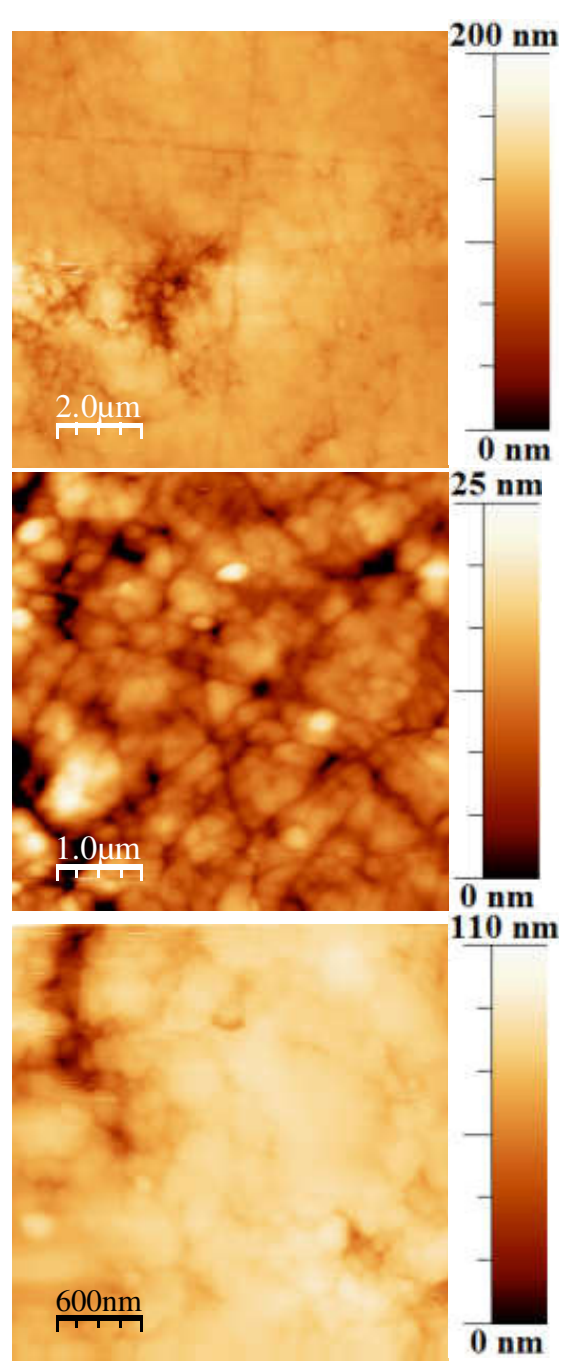

(a)

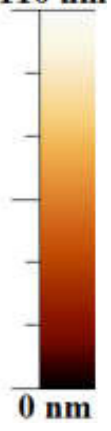

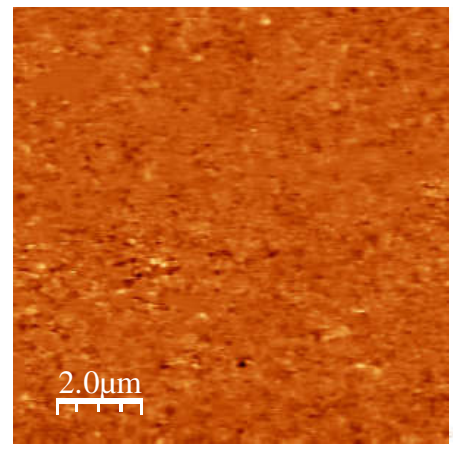
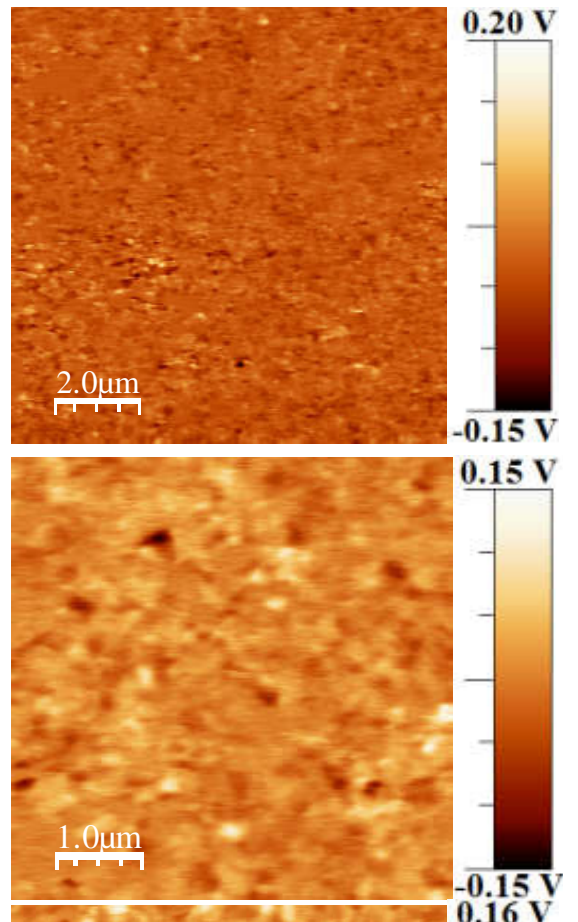

Fig. 11. (a) topography, (b) IP, (c) OPP images KNN-1, KNN-2 and KNN-3 ceramics.

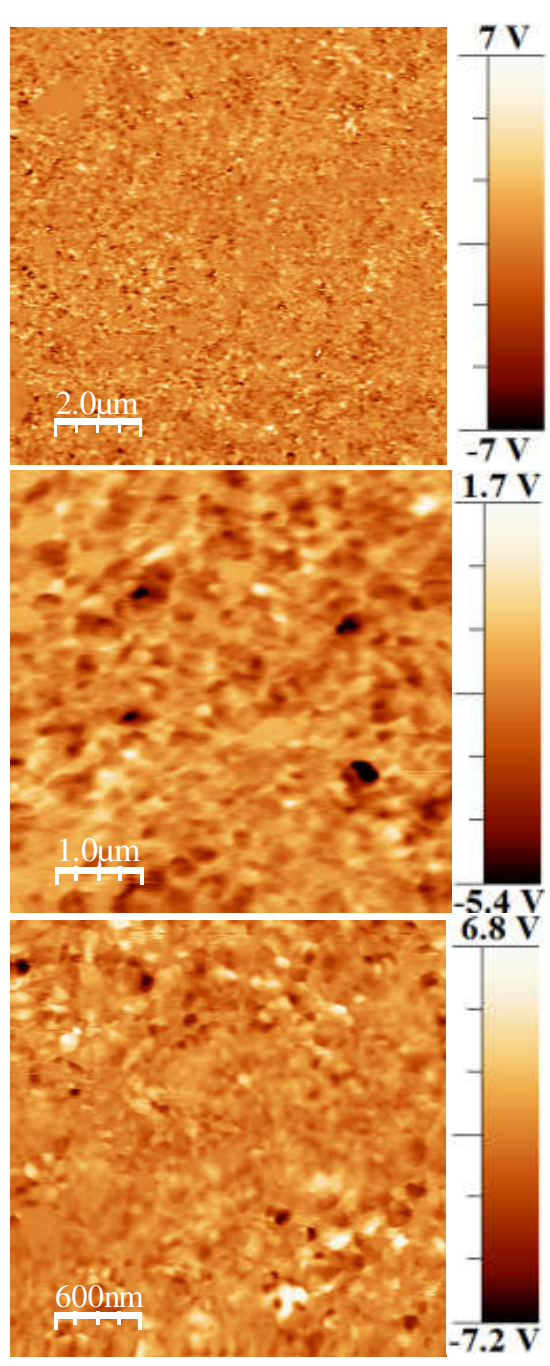

(c)

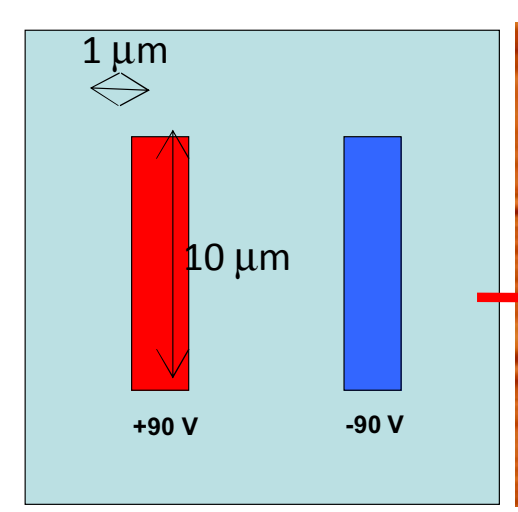

(a)

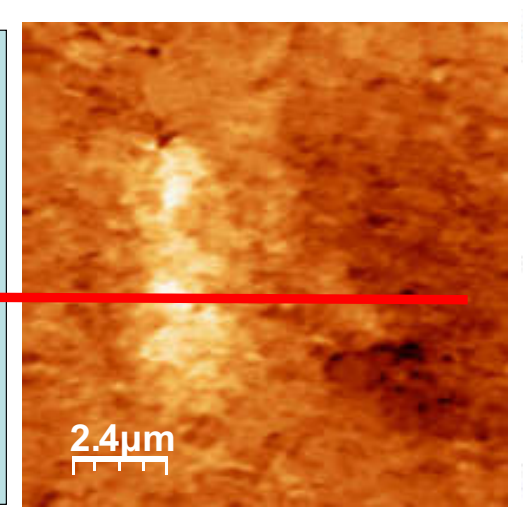

(b)
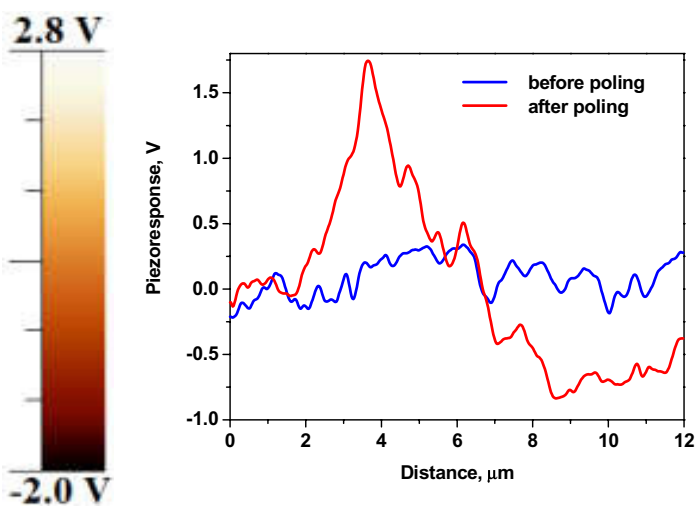

(c)

Fig. 12. (a) Schematic illustration poling, (b) PFM image. (c) cross-section KNN-3 ceramics. 
all ferroelectrics exhibit piezoelectricity, an electric field applied to a ferroelectric sample results in changes to its dimensions. To detect the polarization orientation, the AFM tip is used as a top electrode which is moved over the sample surface.

The OPP and IPP PFM images of the same area of the sample in Fig. 11 show the signal distribution of the piezoelectric response. Figure 11 shows the topography and corresponding $d_{33}$ and $d_{15}$ piezoelectric contrasts. The OPP contrast should contain different signal levels corresponding to 'positive' and 'negative' grains orientations.

RMS $=4.1 \mathrm{~nm}$

Grain size $\sim$ KNN1 - $150 \mathrm{~nm}$.

In order to get a better insight into the polarization switching under an external bias, a dc voltage $(+90 \mathrm{~V}$ and $(-90 \mathrm{~V})$ was applied to the bottom electrode while the grounded tip was scanned across the sample surface. Figure 12 displays the OPP piezoresponse image after poling an area of $1 \times 10 \mu \mathrm{m}^{2}$ inside a larger (un-switched) region of $10 \times 10 \mu \mathrm{m}^{2}$ (Fig. 12(a)). Since the applied voltage was by far greater than the nucleation bias, one can see additional positive and negative contrast, indicating a full polarization switching in them. Figure 12(c) represents the PFM signal cross-sections taken along the lines marked in the piezoresponse image of the poled sample (Fig. 12(b)).

\section{Conclusion}

In this study, we utilized the traditional high-temperature solidstate reaction method to fabricate the $\mathrm{K}_{0.495} \mathrm{Na}_{0.520} \mathrm{NbO}_{3}$, $\mathrm{K}_{0.480} \mathrm{Na}_{0.535} \mathrm{NbO}_{3}$ and $\mathrm{K}_{0.475} \mathrm{Na}_{0.540} \mathrm{NbO}_{3}$ lead-free ion deficient ceramics for understanding the influences of ionic deficiency on the crystalline structure, and dielectric/piezoelectric properties of the samples. XRD pattern confirms that KNN-1 has monoclinic phase whereas in $\mathrm{KNN}-2$ and $\mathrm{KNN}-3$, it confirms the existence of the orthorhombic structure. It also confirms that crystallinity decreases with $\mathrm{Na}$ concentration. $\mathrm{KNN}-2$ and $\mathrm{KNN}-3$ ceramics have a two phase transitions at $287^{\circ} \mathrm{C}$ and $471^{\circ} \mathrm{C}$. The first phase transitions representing the orthorhombic to tetragonal (at $T^{1}$ ) and second phase transitions representing tetragonal to paraelectric cubic (at $T^{2}$ or $T_{c}$ ) transitions. It is also observed that with an increase of $\mathrm{Na}$, the dielectric constant decreases corresponding to the ferroelectric-paraelectric phase transition, but the $T^{1}$ phase transition peaks shifted to a little lower temperature from $454^{\circ} \mathrm{C}$ to $422^{\circ} \mathrm{C}$. An impedance study was conducted for the first time to evaluate the effect of the ion deficient in the structure as a secondary grain boundary phase. The semi-circular arc was depressed and the center of the arc was below the $x$-axis. This behavior indicates that this sample has a poly-dispersive nonDebye behavior. PFM displays the OPP piezoresponse image after poling areas of $1 \times 10 \mu \mathrm{m}^{2}$ inside a larger (un switched) region of $10 \times 10 \mu \mathrm{m}^{2}$. Since the applied voltage was by far greater than the nucleation bias, one can see additional positive and negative contrast indicating a full polarization switching in samples.

\section{Acknowledgment}

Radheshyam Rai and D. V. Karpinsky are grateful to the DST (INT/RUS/RFBR/P-299) New Delhi and RFBR (\#17-5845026 IND_a) Moscow for financial support.

\section{References}

${ }^{1}$ A. Datta, D. Mukherjee and S. Kar-Narayan, Metal Oxide-Based Thin Film Structures (Elsevier, 2018), pp. 465-488.

${ }^{2}$ J. Koruza, A. J. Bell, T. Frömling, K. G. Webber, K. Wang and J. Rödel, J. Materiomics 4, 13 (2018).

${ }^{3}$ J. Luo, W. Sun, Z. Zhou, Y. Bai, Z. J. Wang, G. Tian, D. Chen, X. Gao, F. Zhu and J.-F. Li, ACS Appl. Mater. Interfaces 9(15), 13315 (2017).

${ }^{4}$ J. Gao, X. Hu, Y. Wang, Y. Liu, L. Zhang, X. Ke, L. Zhong, H. Zhao and X. Ren, Acta Mater. 125, 177 (2017).

${ }^{5}$ K. Chandra, A. Kulkarni and K. Prasad, J. Adv. Dielectr. 7(4), 1750025 (2017).

${ }^{6}$ R. Yuan, D. Xue, Y. Zhou, X. Ding, J. Sun and D. Xue, J. Appl. Phys. 122(4), 044105 (2017).

${ }^{7}$ N. Chaiyo, D. P. Cann and N. Vittayakorn, Mater. Des. 133, 109 (2017).

${ }^{8}$ D. Chen, C. T. Nelson, X. Zhu, C. R. Serrao, J. D. Clarkson, Z. Wang, Y. Gao, S.-L. Hsu, L. R. Dedon and Z. Chen, Nano Lett. 17(9), 5823 (2017).

${ }^{9}$ T. Rojac, A. Bencan, G. Drazic, N. Sakamoto, H. Ursic, B. Jancar, G. Tavcar, M. Makarovic, J. Walker and B. Malic, Nat. Mater. 16(3), 322 (2017).

${ }^{10}$ A. Agbelele, D. Sando, C. Toulouse, C. Paillard, R. Johnson, R. Rüffer, A. Popkov, C. Carrétéro, P. Rovillain and J. M. Le Breton, Adv. Mater. 29(9), 1602327 (2017).

${ }^{11}$ K. Xu, J. Li, X. Lv, J. Wu, X. Zhang, D. Xiao and J. Zhu, Adv. Mater. 28(38), 8519 (2016).

${ }^{12}$ P. Bomlai, P. Wichianrat, N. Muensit and S. Milne, Journal of the American Ceramic Society 90(5), 1650 (2007).

${ }^{13}$ C. W. Ahn, S. Y. Lee, H. J. Lee, A. Ullah, J. S. Bae, E. D. Jeong, J. S. Choi, B. H. Park and I. W. Kim, J. Phys. D, Appl. Phys. 42(21), 215304 (2009).

${ }^{14}$ A. Roelofs, T. Schneller, K. Szot and R. Waser, Appl. Phys. Lett. 81(27), 5231 (2002).

${ }^{15}$ P. Mahesh and D. Pamu, Thin Solid Films 562, 471 (2014).

${ }^{16}$ S. Kumar, N. Ahlawat and N. Ahlawat, J. Integr. Sci. Technol. 4(1), 10 (2016).

${ }^{17}$ K. L. Ngai and R. W. Rendell, Phys. Rev. B 61(14), 9393 (2000).

${ }^{18}$ A. Singh, S. Suri, P. Kumar, B. Kaur, A. K. Thakur and V. Singh, J. Alloys Compd. 764, 599 (2018).

${ }^{19}$ J. T. Irvine, D. C. Sinclair and A. R. West, Adv. Mater. 2(3), 132 (1990).

${ }^{20}$ A. Shukla, R. Choudhary and A. Thakur, J. Phys. Chem. Solids 70(11), 1401 (2009).

${ }^{21}$ P. Kumari, R. Rai and A. Kholkin, J. Alloys Compd. 637, 203 (2015).

${ }^{22}$ E. Mensur-Alkoy, A. Berksoy-Yavuz and S. Alkoy, Ferroelectrics 447(1), 95 (2013). 